\title{
Geodetic Basis used during the Remediation of Strečno Cliff
}

\author{
Anna Seidlová ${ }^{1,}$, Jaroslav Síma ${ }^{1}$, and Jakub Chromčák ${ }^{1}$ \\ ${ }^{1}$ Department of Geodesy, Faculty of Civil Engineering, University of Žilina, Slovakia
}

\begin{abstract}
Great part of Slovak traffic is led by the highways nowadays. There is a number of critical parts in highway from Bratislava to Košice, the most critical is under the castle Strečno. In the future, there are plans to redirect the traffic during the tunnel, but in present the traffic goes through road I/18. This is placed between Váh River and the castle, which is placed on the cliff above the road. The flooding and the gradual collapse of cliff accompanied by falling of rock pieces on the communication is very dangerous. The access on the castle walls is almost impossible, it is necessary to use new technologies. The imagining was done by UAV equipment Microkopter and uncalibrated camera with CMOS Full Frame. The result of the work is photoplan with dangerous parts overdrawn. These can be helpful during the remediation.
\end{abstract}

\section{Introduction}

The castle of Strečno is reconstructed ruin of the medieval castle with irregular shape increasing round the centre in National park of Malá Fatra. The castle is placed $11 \mathrm{~km}$ away from Žilina city in region of Považie over the Váh River on 103 meters high dolomite and limestone cliff.

The castle was constructed on the older base of Slavic fort from medieval. In the 1350 is dated the creation of the castle centre with polygonal shape with total area round $400 \mathrm{~m}^{2}$, also called the "small castle" constructed from a prismatic watchtower, a ditch excavated in the rock and the small residential building placed on the NW edge of the fortification. The castle was from the beginning used as a protection of toll gate, placed by the ford through river Váh. The first written mention is dated back to 1316. After World War Second was the castle reconstructed and from 1995 it is available to the general public.

Over time, the cliff began to fall apart due to the excess vegetation and the climatic influences. The whole has been observed for two decades, the biggest shift was observed in 2014, when the whole rock overflow started to deviate and threatened the traffic jam and further traffic consequences, cause the I. class road number I/18 is the fastest and shortest way from Žilina to Martin city. At Figure 1, there is possible to see the covering with plants on the cliff. This vegetation is the greatest indicator of alarming status of this natural monument.

\footnotetext{
* Corresponding author: anna.seidlova@fstav.uniza.sk
} 


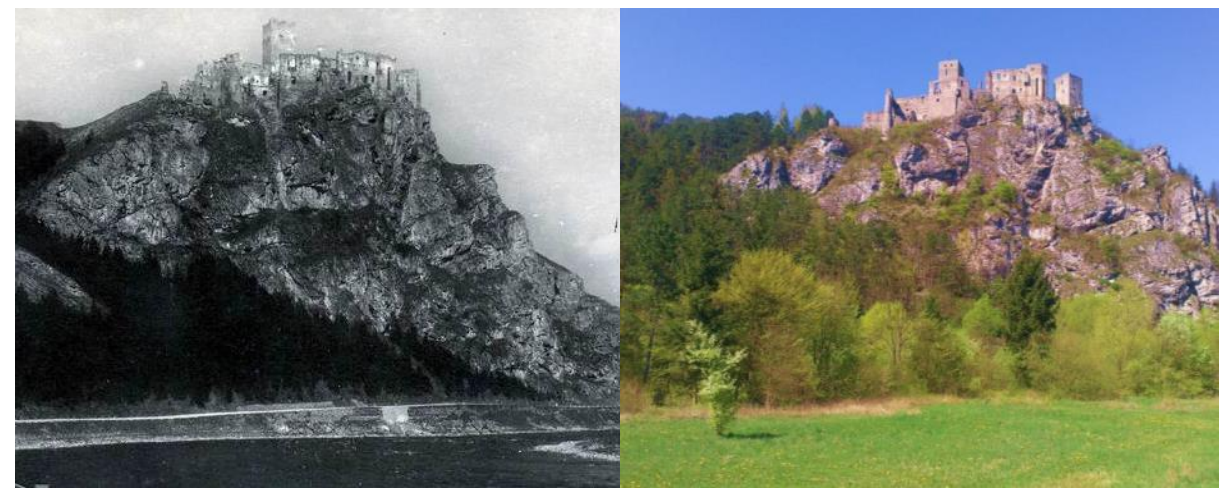

Fig. 1. Image of Strečno castle from 1950 on left and from 2017 on right side

\section{Methods used for the collecting of data}

Due to the work, climatic conditions and position of the castle, there were used two geodetic methods. As the first method it was used forward intersection from angles realised under the cliff from the opposite side of Váh and as the second method was used digital photogrammetry by using of unmanned aerial vehicle. The digital photogrammetry is using the digital images. This image can be taken directly by using of digital camera or indirectly by digitalisation of the analogue images on precise scanners.

\subsection{Unmanned Aerial Vehicle (UAV)}

As the one photogrammetry possibility was chosen UAV method that was the best possibility for the project. UAV can be remotely controlled or can fly independently by using pre-programmed flight plans. They have very wide use in all fields of geographic information and their potential can be used in cases, when the use of classical manned vehicles can't be used. The innovations started in 1900 with the primary focus to provide practical objectives for the training of military personnel. The main advantages of UAV are the price of measurement, the quality of the images, the resolution, the ability to produce digital terrain and surface models, cubic calculations, video documentation and the price of entire facility as well.

\section{Fieldworks}

The imagining was realised by using of UAV- Microkopter and uncalibrated camera with CMOS Full Frame chip $36 \mathrm{MPx}$ with objective type FE 35mm F2.8 ZA. The number of images, that has Microcopter made was 168 with average flight elevation 102,2m and with number of tie-points in total sum 993 324. The error of orientation was 0,363 pixels and the size of pixel was $0,0134 \mathrm{~m}$ that shows the great quality of analysed data. For the coordination and shaping and sizing of whole situation, there were defined the 3D coordinates at the cliff, castle wall and at the communication $\mathrm{I} / 18$.

The control points were measured from the points of a minor control, defined by GNSS method using of the permanent stations of SmartNet network with declared precision of $2 \mathrm{~cm}$. With this technology it could be obtained precision to $3 \mathrm{~cm}$ in position and $1,5 \mathrm{~cm}$ in elevation. The coordinates of the control points are displayed in Table 1. At Figure 2 there is also displayed the position of the points. 
Table 1. Coordinates of control points.

\begin{tabular}{|r|c|c|c|}
\hline number & $\mathrm{Y}$ & $\mathrm{X}$ & $\mathrm{H}$ \\
\hline 5001 & 434743.41 & 1178236.05 & 468.41 \\
\hline 5002 & 434750.37 & 1178248.70 & 472.08 \\
\hline 5003 & 434752.63 & 1178263.21 & 467.14 \\
\hline 5004 & 434759.50 & 1178271.77 & 464.06 \\
\hline 5005 & 434750.15 & 1178267.45 & 438.92 \\
\hline $5006 \mathrm{~A}$ & 434741.49 & 1178247.28 & 438.64 \\
\hline $5006 \mathrm{~B}$ & 434738.60 & 1178249.43 & 437.42 \\
\hline 5007 & 434740.55 & 1178239.15 & 450.41 \\
\hline 5008 & 434703.47 & 1178257.34 & 364.94 \\
\hline 5008 & 434703.47 & 1178257.34 & 363.21 \\
\hline 5009 & 434700.38 & 1178239.52 & 363.25 \\
\hline 5010 & 434697.29 & 1178221.83 & 363.19 \\
\hline 5011 & 434694.21 & 1178204.26 & 363.26 \\
\hline 5020 & 434678.36 & 1178097.80 & 364.46 \\
\hline
\end{tabular}

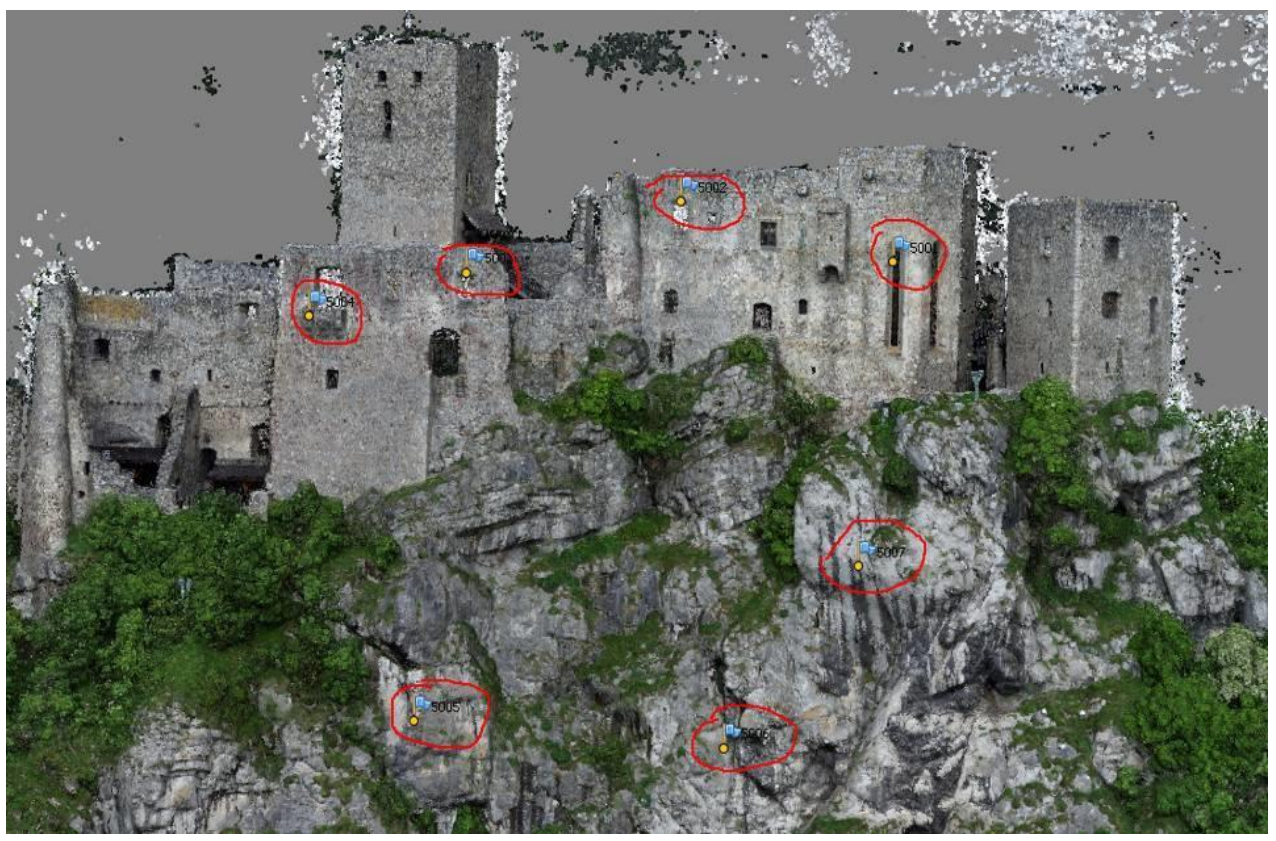

Fig. 2. The placing of control points at the cliff and castle walls

The correction of georeferenced images in the inner aerotriagnulation were checked by using of AGI Soft. The images were georeferenced by using of natural control points. Before the calculation were these points chosen and defined at the cliff and after that defined at the images created from UAV imagining. 
At the and there was created a point cloud from georeferenced images in regular grid with size $10 \times 10 \mathrm{~cm}$. Working with the program Agisoft PhotoScan made possible to create orientation, georeferenced, calculation of point cloud but creation of texture model as well. After the model creation were created the sections in scale 1:200 and 1:400, perspective drawing of the contour lines and displaying of level planes into the photoplan- this was possible to do by using program MicroStation Descartes.

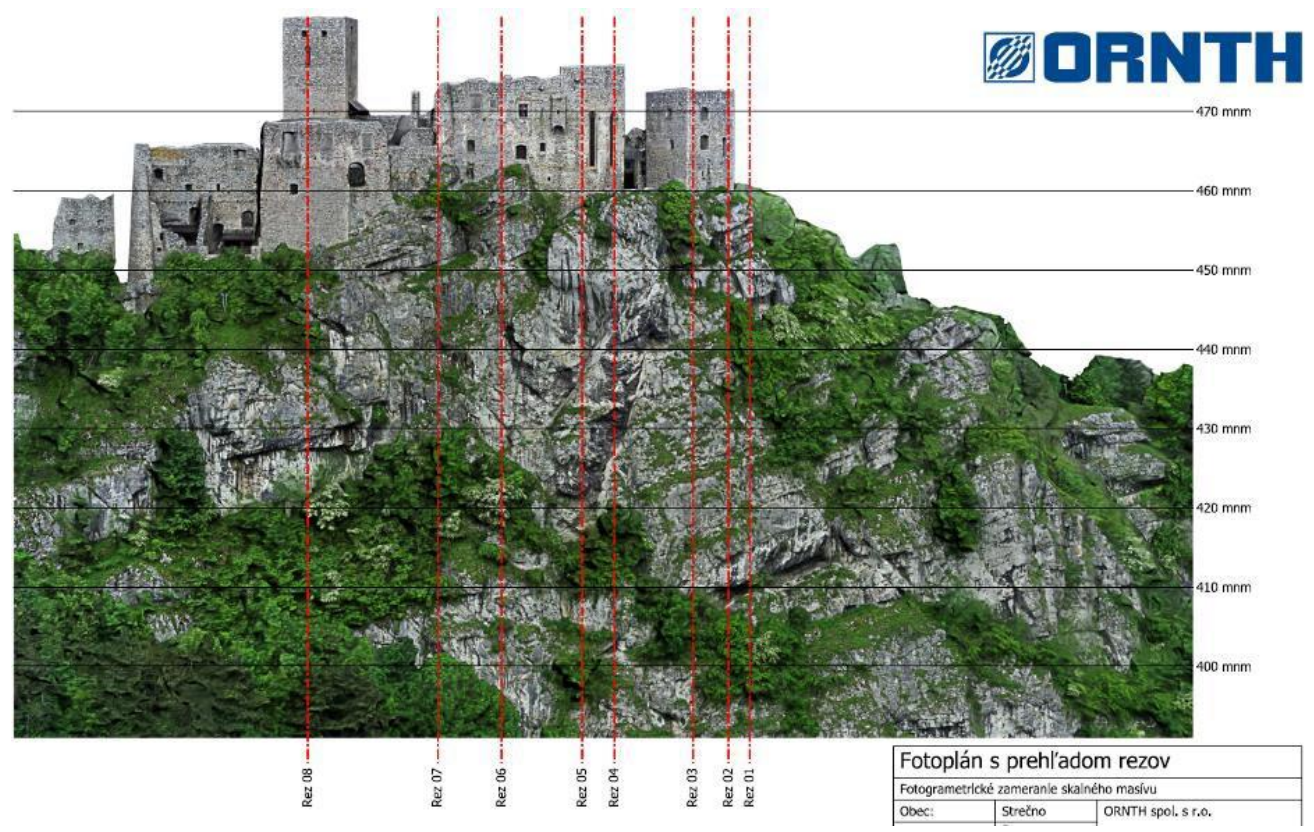

Fig. 3. The scheme of sections (red colour) and drawing of the elevation

\section{Calculation of the capacity}

During the evolution of the mathematical methods used in geodesy, as well as developing of the geodetic equipment (total stations, 3D laser scanners and so), the number and type of methods has changed. The number of method is based on using elementary mathematical relations, the other are using integral calculations. Method of capacity calculation from the sections is often used for calculation of irregular shaped objects. It is the best option if it is impossible to use block calculations.

In total cloud with density $10 \times 10 \mathrm{~cm}$ were step by step calculated coordinates of blocks. They were collected and closed into vertical planes, which were representing the castle wall in given area.

Table 2. Capacity of hazardous blocks.

\begin{tabular}{|c|c|c|}
\hline Block I. & yellow & $1182 \mathrm{~m}^{3}$ \\
\hline Block II. & blue & $690 \mathrm{~m}^{3}$ \\
\hline Block III. & purple & $240 \mathrm{~m}^{3}$ \\
\hline
\end{tabular}




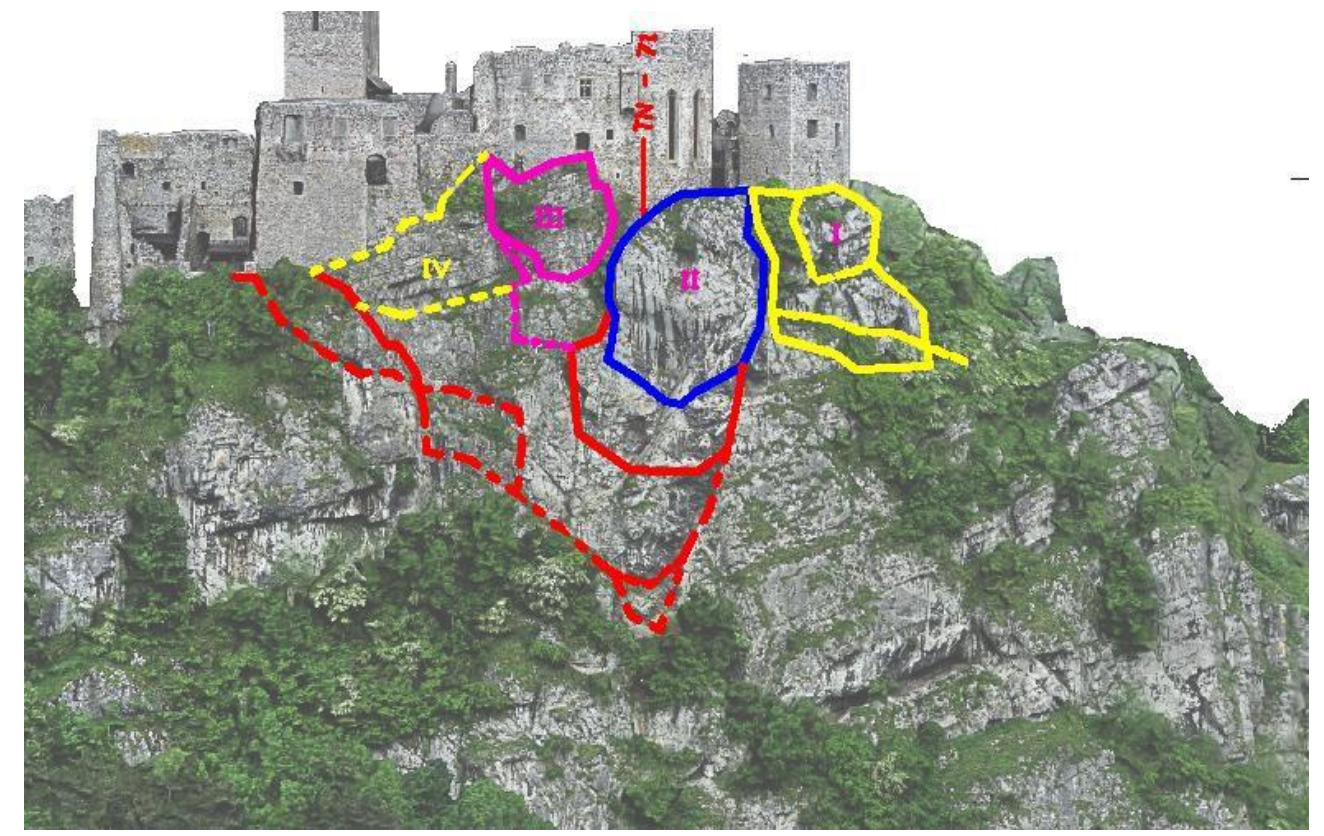

Fig. 4. Schematic presentation of blocks, their capacity was calculated

\section{Precautions}

In 1984 was done the first remediation of the cliff. The stability of the cliff was secured by the reinforcements and the grouting. The cliff was also secured by using of steel ropes. Nowadays, 31 years from the remediation, the rocks have been still hummed and they are disengaging. The most critical part of the cliff is its' critical blocks and overflows, which need the remediation immediately. In the cliff there is regular system of cracks that are the reasons of local landslides. These can be dangerous for the communication under cliff.

As a solution of situation was proposed combination of two options. First one is the remediation of some cliff parts and the second is the construction of a gallery to protect traffic from the rocks falling. The rock can be repaired by sealing or by placing of protective multi-barriers, cement mortar, reinforcing concrete reinforcement with build-in drainage, the concrete steals and limestone cleaning. Another possible solution is to use the fixing anchors.

\section{Conclusions}

Thanks to its historical castle, traditional plains and the beautiful nature, Strečno area is an international tourist destination. If the problem resulting from the instability of cliff causes danger or death, it would have serious effect to the tourism in area. The aim of paper was to focus on troubles and complications with the remediation of the cliff by using of UAV system and subsequent imaging of the object. From the images was created a detailed model of the situation. There are displayed the places, where the rock is shifting and the rock is disintegrating. 
This article is the result of the implementation of the project VEGA 1/0275/17 "Application of numerical methods to define the changes of geometrical track position" supported by the Scientific Grant Agency of the Ministry of Education, science, research and sport of the Slovak Republic and the Slovak Academy of Sciences. This article is the result of the implementation of the project ITMS 26220220156 "Broker centre of air transport for transfer of technology and knowledge into transport and transport infrastructure" supported by the Research \& Development Operational Programme funded by the ERDF.

\section{References}

1. Rakús and col., Geological map of Malá Fatra mountains in scale 1:50 000. ISBN: 50/289/91-1 (GÚDŠ, 1993)

2. Pisca P., Censek T., Digital Photogrammetry for cracks monitoring, ISSN 1314-2704 (SGEM 2017)

3. Roux S., Réthoré J., Hild F., Digital image correlation and fracture: an advanced technique for estimating stress intensity factors of $2 D$ and $3 D$ cracks, Journal of Physics D: Applied Physics (2009)

4. Lambers K., Remondino R., Optical 3D measurement techniques in archaeology: recent developments and applications, International Conference on Computer Applications and Quantitative Methods in Archaeology (Berlin 2007) 